Ensino, Saúde e Ambiente - v. 14 n. esp. (2021): Dossiê Paulo Freire para além dos 100 anos:

construir utopias, transformar a realidade, p. 659-684.

Estética, Cinema, Teatro, Comunicação

ENSINO, SAÚDE E AMBIENTE

\title{
Educação libertadora e teatro político em tempos de denúncia e anúncio
}

\section{Liberating education and political theater in times of denunciation and annunciation}

\author{
Hélio Junior Rocha de Lima ${ }^{1}$; Hostina Maria Ferreira do Nascimento² ${ }^{2}$ Maria Cleonice Soares ${ }^{3}$ \\ 1 Doutor em Estudos da Linguagem, Universidade do Estado do Rio Grande do Norte, Mossoró, RN, Brasil - E-mail: \\ heliojunior@uern.br / ORCID https://orcid.org/0000-0003-4353-7003 \\ 2 Doutora em Educação, Universidade do Estado do Rio Grande do Norte, Mossoró, RN, Brasil - E-mail: \\ hostinamaria@uern.br / ORCID https://orcid.org/0000-0003-2403-9236 \\ 3 Mestre em Educação, Universidade do Estado do Rio Grande do Norte, Mossoró, RN, Brasil - E-mail: \\ cleonicesoares@uern.br/ORCID https://orcid.org/0000-0003-2772-7384
}

Palavras-chave: círculo de cultura; Lefreire; teatro do oprimido; teatro imagem.

Keywords: culture circle; image theater; Lefreire; theater of the oppressed.
RESUMO: Esta pesquisa traz reflexões e questões acerca da educação libertadora desenvolvida nos círculos de cultura do Grupo LEFREIRE - Diálogos em Paulo Freire e Educação Popular - que têm modalidades fundamentadas na Pedagogia e no Teatro do Oprimido como principal ponto de partida para o diálogo entre os participantes. Com referência à pesquisa participativa e experimental tem-se, como materiais e arquivos para realização deste estudo, o registro escrito e gravações dos círculos, assim como os encontros para avaliação e reelaboração, produções de imagens, textos e relatos dos ensaios. Verificou-se, em contexto pandêmico, a criação de um laboratório virtual no projeto de extensão Teatro imagem na sala de aula, integrante do LEFREIRE, no qual foram realizados experimentos com imagens paradas e em movimentos, e ensaiadas possibilidades de jogos cênicos interativos que resultaram na produção de um texto dramático em formato de fotonovela contracenado virtualmente com espectadores/espectadoras. Observando as funções do animador ou coordenador dos círculos e do coringa, conferencista ou exegeta, do teatro do oprimido e considerando que as ações dos dois não se propõem como bancárias, indaga-se como os pensamentos de Boal e Freire se cruzam nos círculos lefreireanos. O coordenador/facilitador dos círculos de cultura e o animador/coringa do teatro do oprimido vislumbram e compartilham utopias? As reflexões desenvolvidas evidenciam a comunhão entre os pensamentos críticos norteadores das ações tanto da educação libertadora como do teatro do oprimido que fez emergir, neste campo pedagógico ativo e inventivo, experimentos virtuais com imagens e palavras transformadas em temas geradores problematizados nos círculos lefreireanos.

ABSTRACT: This research brings reflections and questions about the liberating education developed in the culture circles of the LEFREIRE Group - Dialogues in Paulo Freire and Popular Education - which had modalities based on the theater of the oppressed as the main starting point for the dialogue and interventions of the participants. Referencing participatory and experimental research, are used, as materials and files for this study, the written register and recordings of culture circles, as well as meetings for their evaluation and re-elaboration and experiences with theater, image productions and texts, reports of essays. It was verified, in a pandemic context, the creation of a virtual dramatic laboratory in the extension project "Image 
Ensino, Saúde e Ambiente - v. 14 n. esp. (2021): Dossiê Paulo Freire para além dos 100 anos:

construir utopias, transformar a realidade, p. 659-684.

\author{
Estética, Cinema, Teatro, Comunicação
}

theather in the classroom", part of LEFREIRE, in which experiments were carried out with still and moving images, and were tested possibilities of interactive scenic games that resulted in the production of a dramatic text in the form of a photo-novel staged virtually with spectators. Observing the functions of the animator or coordinator of the circles and the lecturer or exegete 'joker' of the theater of the oppressed, and considering that the actions of the two are not intended as banking, one wonders how the thoughts of Augusto Boal and Paulo Freire intersect in Lefreirean circles. The culture circles animator's and the joker of the theater of the oppressed glimpse and share utopias? The reflections developed by the research show the communion between the critical thoughts guiding the actions of both liberating education and the theater of the oppressed, which gave rise, in this active and inventive pedagogical field, to virtual experiments with images and words transformed into generative themes problematized in Lefreirean circles.

Os cem anos de Paulo Freire, tempo de celebração, coincidem com o contexto de crise humanitária e ambiental provocada pela profunda desigualdade que marca a sociedade capitalista global. Desigualdade escancarada pela pandemia do Covid-19 ${ }^{1}$. Tal coincidência, longe de ser motivo para estagnação, se revela como momento profícuo para recriar a ebulição política dos que não se conformam apenas em lançar holofotes ao Patrono da Educação Brasileira e colher raios de luz sobre si mesmos.

Neste momento histórico de profunda opressão, de acirramento da negação do amor e da vida, a educação há que cultivar o exercício criativo e criador coletivo contra a desesperança, problematizando a realidade em busca de inéditos-viáveis a serem construídos. É um tempo profícuo para compreender a amplitude do pensamento de Freire sobre educação e, humildemente, perguntar que ações fundamentadas nesta epistemologia estão conseguindo sair do discurso e se efetivar em transformações coletivas.

Entre as contribuições de Paulo Freire à transformação da sociedade brasileira, os círculos de cultura floresceram nas décadas de 50 e 60 do século passado como dispositivo da sua proposta de educação libertadora. Num período tão forte como hoje de emergências populares, e também de oportunismos populistas, havia, entre os grupos comprometidos com iminentes transformações da realidade brasileira, a perspectiva de emancipação de uma ínfima, incipiente e ineficiente democracia.

Nesta perspectiva emancipadora da sociedade e da democracia surgiram movimentos populares como o Movimento de Cultura Popular - MCP, no Recife, em Pernambuco; o

\footnotetext{
${ }^{1}$ Doença infecciosa causada pelo novo coronavírus, identificado pela primeira vez em dezembro de 2019, em Wuhan, na China. A pandemia foi decretada em março de 2020, quando a doença se espalhou pelo mundo. Fonte: https://www.paho.org/pt/covid19.
} 
Ensino, Saúde e Ambiente - v. 14 n. esp. (2021): Dossiê Paulo Freire para além dos 100 anos: construir utopias, transformar a realidade, p. 659-684.

\section{Estética, Cinema, Teatro, Comunicação}

Movimento Educação de Base - MEB, vinculado à Conferência Nacional dos Bispos do Brasil - CNBB; e os Centros Populares de Cultura - CPCs.

Conforme Oliveira (apud GERMANO, 1981), o Nordeste do país contextualizou forte ascensão de vários destes movimentos: o apoio da Igreja Católica à reforma agrária; a organização das Ligas Camponesas para combater a propriedade latifundiária e o sobretrabalho; e as práticas e discussões do MCP e de Paulo Freire, não somente de/sobre a valorização da cultura popular, mas também da desmistificação dos processos de dominação e exploração.

Os movimentos desencadeados no Nordeste brasileiro reverberavam mobilizações políticas que se davam nos grandes centros urbanos, especialmente do Sudeste. Em meados dos anos cinquenta, como manifestações da pequena-burguesia, ações teatrais desencadearam os seminários de dramaturgia que, potencialmente, desaguaram na criação do CPC junto à União Nacional dos Estudantes - UNE.

A arte dramática desenvolvida nos grupos como o TPE - Teatro Paulista de Estudantes, Teatro de Arena e Teatro Oficina buscavam uma forma de fazer teatro considerando as aspirações populares e o enfrentamento à cultura de massa e à alienação, também massificante, por ela produzida. Os CPCs atuavam com o assunto do momento, num dinamismo que objetivava alcançar as classes populares, refutando o teatro feito em pequenos espaços e para um público seleto de intelectuais (GUIMARÃES, 1984). Fazendo frente às reproduções de temas psicológicos e às peças importadas, a inquietação dos fazedores desse teatro delineava pensamentos e ações nacionais críticos, considerando a necessidade de uma temática genuinamente brasileira que desse relevo aos problemas sociais do país. O pensamento de Augusto Boal é parte deste movimento político revolucionário na forma de fazer teatro. No âmbito do Teatro de Arena nasceram os primeiros passos de uma técnica de representação com o sistema coringa ${ }^{2}$, contrariando as convenções teatrais clássicas.

Neste contexto de ações políticas e sociais libertadoras surgiram diversos movimentos e campanhas de educação destinadas às camadas populares, tanto para a escolarização elementar quanto para a alfabetização de adultos, como foi o caso da emblemática campanha “De pé no chão também se aprende a ler" desenvolvida em Natal, no Rio Grande do Norte.

Envoltas neste contexto se forjaram as primeiras experiências pedagógicas freireanas, entre elas o movimento conhecido como "As quarenta horas em Angicos”, no início de 1963,

\footnotetext{
${ }^{2} \mathrm{~A}$ escrita com "u" - curinga - também é utilizada por alguns praticantes do teatro do oprimido.
} 
Ensino, Saúde e Ambiente - v. 14 n. esp. (2021): Dossiê Paulo Freire para além dos 100 anos: construir utopias, transformar a realidade, p. 659-684.

\section{Estética, Cinema, Teatro, Comunicação}

patrocinado pelo Governo do Estado Rio Grande do Norte, uma nítida situação em que interesses populistas oportunos abriram espaço para ações populares voltadas à transformação.

Objetivando realizar a alfabetização de adultos pautada na conscientização, de maneira que os participantes, em 40 horas de estudo, aprendessem a ler e a escrever com compreensão crítico-reflexiva sobre sua realidade, em meados de "dezembro de 1962, um grupo de estudantes, em sua maioria universitários, liderados por Paulo Freire, realizou o levantamento do universo vocabular da população de Angicos, preparando o terreno para a experiência que viria a seguir" (GERMANO, 1997, p. 389). Assim, nos primeiros meses de 1963, foram organizados e realizados os círculos de cultura angicanos, lugares de esperança e realização.

Forjada, inicialmente, nas experiências pedagógicas adequadas à alfabetização de adultos crítica e reflexiva, a proposição freireana não se limitou à mobilização e agilização desta prática alfabetizadora, mas se comprometeu, desde o princípio, com uma educação libertadora, em seu sentido mais amplo. Compromisso, este, que se consolidou na história da educação brasileira e mundial.

\section{PEdAgogia E TEATRO COMO AÇÃo Libertadora NO CÍRCULO DE CULTURA}

Desmistificado o equivocado caráter estritamente alfabetizador da proposta de Freire, descortina-se sua Pedagogia do Oprimido desdobrada em contribuições não só à educação, mas para diversas áreas da produção do conhecimento. Neste contexto situa-se o círculo de cultura, lugar de (auto) conhecimento da/na cultura, experiência humana crítica e criadora de interação com o mundo, sua diversidade e suas contradições. Muito mais do que espaço-tempo de valorização e absorção da cultura, os círculos se realizam numa práxis de releituras e reflexões críticas sobre conhecimentos que a comunidade tem da sua própria realidade ou da sua organização e seus aparelhos sociais. As interações que promovem permitem ampliar o processo de conscientização.

O círculo de cultura [...] re-vive a vida em profundidade crítica. A consciência emerge do mundo vivido, objetiva-o, problematiza-o, compreende-o como projeto humano. Em diálogo circular, intersubjetivando-se mais e mais, vai assumindo, criticamente, o dinamismo de sua subjetividade criadora. Todos juntos, em círculo, e em colaboração, re-elaboram o mundo e, ao reconstruí-lo, apercebem-se de que, embora construído 
Ensino, Saúde e Ambiente - v. 14 n. esp. (2021): Dossiê Paulo Freire para além dos 100 anos: construir utopias, transformar a realidade, p. 659-684.

\section{Estética, Cinema, Teatro, Comunicação}

também por eles, esse mundo não é verdadeiramente para eles. Humanizado por eles, esse mundo não os humaniza. As mãos que o fazem, não são as que o dominam. Destinado a liberá-los como sujeitos, escraviza-os como objetos (FIORI, 2005, p. 17).

De forma crítica e reflexiva, coletivamente, os fenômenos e situações-limites presentes nas realidades são colocados em diálogo de maneira a construir conhecimentos que contribuam à transformação coletiva destas realidades. Nesta interação problematizadora, as pessoas vão se percebendo e se colocando enquanto tal e, paulatinamente, desenvolvendo/ampliando a consciência de si e para si através de processos construídos na dialética indivíduo-coletivo e não pela "justaposição de informes ou prescrições doadas" (FREIRE, 2005). Processo cuja constância imprime, no coletivo, a leitura das relações humanas e de seus desafios.

O principal destes desafios é a superação das relações de opressão que se manifestam, sobretudo, pela dominação e exploração dos seres humanos uns sobre os outros (mas também destes sobre os outros animais e sobre a natureza em geral) ${ }^{3}$. Paulo Freire as compreende como manifestação máxima da desumanização, distorção da vocação humana em "ser mais", uma vez que "[...] a desumanização, mesmo que um fato concreto na história, não é, porém, destino dado, mas resultado de uma 'ordem' injusta que gera a violência dos opressores e, esta, o ser menos" (FREIRE, 2005, p. 32).

Esta (des)ordem injusta decorrente da dominação e exploração se desdobra em distorções e desigualdades sociais relativas, especialmente, às implicações da mais-valia, da exploração da força de trabalho e dos problemas de subjugação ao mercado. Neste contexto, aspectos das culturas dominantes reforçadores de processos de exclusão (sejam sociais, raciais, étnicos, sexistas, homofóbicos, religiosos, da exploração do trabalho) estão impregnados nos diversos grupos culturais oprimindo as minorias marginalizadas.

Desta maneira, o caráter exploratório e ideológico que comporta as relações sociais nem sempre permite a contemplação espontânea de valores humanamente libertadores. Em decorrência, alguns grupos sociais, mesmo quando têm acesso aos bens disponibilizados na sociedade, como é o caso da alfabetização e do letramento, por vezes se encontram em situação de aceitação das relações opressoras naturalizadas pela cultura.

Pela sua capacidade de reprodução, as realidades opressivas atingem e impregnam a todos os núcleos sociais presentes numa sociedade marcada pela desigualdade, de modo que não se

\footnotetext{
${ }^{3}$ Quando aborda a superioridade dos humanos sobre os outros seres, Freire está se referindo à capacidade humana de raciocínio e de percepção do tempo em sua finitude. O "ser mais" a que esta compreensão se refere implica a percepção planetária da relação de interdependência entre os humanos e os outros seres.
} 
Ensino, Saúde e Ambiente - v. 14 n. esp. (2021): Dossiê Paulo Freire para além dos 100 anos: construir utopias, transformar a realidade, p. 659-684.

\section{Estética, Cinema, Teatro, Comunicação}

pode delinear este ou aquele sujeito ou grupo apenas como opressor ou apenas como oprimido. Freire afirma que antes de mergulharem em um processo de conscientização emancipadora, os oprimidos, quase sempre, tendem a adotar atitudes de "adesão" em relação à opressão.

[...] em lugar de lutar pela liberdade, os oprimidos tendem a converter-se eles mesmos em opressores ou em "subopressores". A própria estrutura de seu pensamento viu-se condicionada pelas contradições da situação existencial concreta que os manipulou. Seu ideal é serem homens, mas, para eles, serem homens é serem opressores. Este é seu modelo de humanidade (FREIRE, 2006a, p. 67).

Nesta condição, é-lhes impossível, num primeiro momento e de forma espontânea/desarticulada, ver estes processos com lucidez suficiente para, objetivando-os, percebê-los "fora de si mesmos", conforme alerta Freire:

\footnotetext{
$\mathrm{Na}$ "imersão" em que se encontram, não podem os oprimidos divisar, claramente a "ordem" que serve aos opressores, que de certa forma, vivem neles. "Ordem" que frustrando-os no seu atuar, muitas vezes os leva a exercer um tipo de violência horizontal com que agridem os próprios companheiros. É possível que, ao agirem assim, mais uma vez explicitem sua dualidade. Ao agredirem seus companheiros oprimidos estarão agredindo neles, indiretamente, o opressor também "hospedado" neles e nos outros. Agridem, como opressores, o opressor nos oprimidos (FREIRE, 1981, p. 53).
}

O fato dos oprimidos "carregarem" em si um opressor decorre das relações opressivas presentes na sociedade e que transpassam a cultura, criando a necessidade de efetivação de atitudes emancipadoras e transformadoras frente às desigualdades estruturadas nas instituições e no fluxo da vida.

Tais questões, entre tantas outras próprias das relações e contradições entre as pessoas e o mundo são "o chão" onde se efetiva a educação libertadora. Amplamente discutidas por Paulo Freire, são verificadas, também, nos escritos de Augusto Boal, definindo seus modos de pensar e refletir as ações teatrais. Entre tantas referências que elucidam sua sistemática teatral, como Aristóteles, Brecht e Marx, explicita-se o teor temático e problematizações aguçadores das lutas cotidianas contra a desigualdade e a opressão. Da mesma forma, a Pedagogia Freireana e o Teatro do Oprimido, criado por Boal, estão pontencializados na luta incessante por direitos e participação social e política. 
Ensino, Saúde e Ambiente - v. 14 n. esp. (2021): Dossiê Paulo Freire para além dos 100 anos: construir utopias, transformar a realidade, p. 659-684.

\section{Estética, Cinema, Teatro, Comunicação}

Esta atuação de, com e para homens e mulheres livres milita transitando pela identificação dos seres em situação, vivenciando limites e se percebendo neles, em um se fazendo que é a própria ação editanda, compreendida por Freire (2006a) como necessária à conscientização e à emancipação, transformando desafios presentes nas realidades em programação de práticas-educativas cujos objetivos correspondam às lutas dos grupos.

O teatro do oprimido, por sua vez, como subversão de uma convenção teatral antiga amalgamada numa ideia de representação de um modo dominante de pensar a arte dramática ${ }^{4}$, já se coloca como processo criativo transgressor dessa ordem. O teatro já se mostra político e perturbador. O discurso se afeta no atravessamento da ação. Uma concepção crítica implicada na ação-reflexão-ação em movimento.

O exercício de criticidade promovido pelo teatro do oprimido permite desconstruir ou mesmo decodificar questões sociais e culturais que tendem a manter a realidade estática, aparentemente imutável, na qual os oprimidos ou naturalizam a opressão e se posicionam passivamente ou a veem como situação-limite. Diante desta abordagem não há mais a possibilidade do espectador permanecer passivo, sem reagir ao conteúdo apresentado em forma de jogo teatral. Não há como esperar por uma mensagem confortadora das suas angústias ou direcionadora de um modelo de ação.

Destarte, o diálogo e a ação-reflexão-ação põem à pedagogia do oprimido e ao teatro do oprimido a possibilidade de vivência de processos de conscientização das situações excludentes presentes nas realidades. E, também, do encontro e da associação potencializadores dos objetivos da práxica que se completa em seus atos. Aí reside a importância crítico-reflexiva dos círculos de cultura como possibilitadores da percepção da interferência das relações opressivas, inclusive daquelas presentes nas suas próprias práticas.

O ponto de partida para o trabalho no círculo de cultura está em assumir a liberdade e a crítica como o modo de ser do homem. [...] O círculo se constitui assim em um grupo de trabalho e de debate. Seu interesse central é o debate da linguagem no contexto de uma prática social livre e crítica. Liberdade e crítica que não podem se limitar às relações internas do grupo mas que necessariamente se apresentam na tomada de consciência que este realiza de sua situação social. (WEFFORT, 2006, p. 15-16)

\footnotetext{
${ }^{4}$ Um teatro centrado na figura autoritária de um diretor, como reprodução dos modelos teatrais mercantilistas, mesmo tratando de temas tidos como revolucionários, tende a cair nas malhas dominadoras e se deixar acontecer pela consciência ingênua.
} 
Ensino, Saúde e Ambiente - v. 14 n. esp. (2021): Dossiê Paulo Freire para além dos 100 anos: construir utopias, transformar a realidade, p. 659-684.

\section{Estética, Cinema, Teatro, Comunicação}

O diálogo produzido nos círculos faz parte de um movimento de ação-reflexão-ação que tem, no seu interior, o exercício da cidadania pelo processo de tomada de consciência que o envolve e no qual estão envolvidos os que dele participam, prolongando-se antes e depois de cada encontro. Isto porque a tomada de consciência dos direitos, em participação, implica em buscar meios de transformação das condições opressoras próprias e produtoras da não participação. Neste processo de conscientização, a experiência coletiva democrática se nutre de esperança ao se fazer exercício de ruptura da cultura de alienação e segregação.

\section{OS CÍRCULOS DE CULTURA LEFREIREANOS}

Toda a questão política e crítica que impregna o círculo de cultura inspira um estado de pertencimento, um sentir-se e perceber-se parte de um grupo. Não se trata de um sentido que transita "de fora para dentro", mas uma compreensão dos significados do ser e do seu lugar. Lendo o mundo de maneira crítica e coletiva, as pessoas vão, paulatinamente, se percebendo e se compreendendo no fazer das práticas da educação libertadora.

Considerando o estado de pertencimento próprio das ações coletivas, se faz necessário problematizar experiências atuais de realização de círculos de cultura, situar desafios e possibilidades criativas e (re)criadoras dessas ações comprometidas com o referencial freireano e compreender a conservação e inovação dos seus dispositivos de atuação.

Imbuídos do sentimento de pertença e interação coletivas, sentimos a necessidade de localizar o lugar de onde estamos traçando estas indagações problematizadoras e as necessidades de ampliação desses estudos como forma de metarreflexão sobre os círculos de cultura que promovemos e que acontecem nos movimentos das ações universitárias de pesquisa-extensão-ensino.

Os círculos de cultura promovidos pelo Grupo LEFREIRE - Diálogos em Paulo Freire e Educação Popular ${ }^{5}$ são rodas de partilha de conhecimentos baseadas na horizontalidade dos saberes, na escuta sensível, na valorização coletiva das falas e expressões, no respeito ao outro,

\footnotetext{
5 Vinculado ao GEPEL - Grupo de Estudos e Pesquisas Educação e Linguagens, da Faculdade de Educação da Universidade do Estado do Grande do Norte, o LEFREIRE, criado em 2009, é composto por alunos e professores da graduação e da pós-graduação e técnicos administrativos da UERN; e por professores da educação popular, da escola pública e da educação de jovens e adultos. Os círculos lefreireanos acontecem em comunidades rurais e escolas públicas do RN e do Ceará; na UERN, com professores, alunos, técnicos de ensino superior e servidores de empresas que prestam serviços terceirizados; e com artistas de Mossoró/RN.
} 
Ensino, Saúde e Ambiente - v. 14 n. esp. (2021): Dossiê Paulo Freire para além dos 100 anos: construir utopias, transformar a realidade, p. 659-684.

\section{Estética, Cinema, Teatro, Comunicação}

no (re) conhecimento de realidades, no aprender e também ensinar e, principalmente, refletir criticamente sobre a vida, suas conquistas e desafios.

Os círculos de cultura lefreireanos objetivam colocar os principais conceitos presentes na obra de Freire em diálogo com a educação popular, a escola pública, movimentos sociais e a realidade de comunidades urbanas e rurais através de atividades teórico-práticas que contribuam para a compreensão e transformação da vida destes grupos e pessoas.

Como grupo forjado nas vivências acadêmicas, procura promover o diálogo entre conhecimentos científicos e saberes e experiências de educação popular e escolar, bem como artísticos-literários. Neste sentido, a articulação entre a epistemologia freireana e o teatro do oprimido promove discussões sobre a pessoa e seu corpo no mundo que potencializam os diálogos nos círculos lefreireanos.

Trata-se de um movimento contínuo de construção do conhecimento no qual as temáticas são definidas através dos estudos de aspectos e fenômenos das realidades dos coletivos com os quais o Grupo interage em suas atividades de pesquisa e extensão que reverberam no ensino-aprendizagem de disciplinas de graduação e de pós-graduação.

Para vislumbrar a atuação do LEFREIRE, a princípio é interessante saber em que campos do conhecimento se fundam as suas ações. Os círculos envolvendo a prática pedagógica e a formação docente inicial e permanente pesquisam a ação-reflexão-ação e a construção e partilha de saberes entre professores ${ }^{6}$. Abordam temáticas que vão desde a presença de salas multisseriadas na educação rural, processos criativos nos jogos e brincadeiras na educação infantil, a importância do ato de ler, a importância dos afetos para o processo de ensino e aprendizagem até a formação e prática dos professores para/no ensino remoto.

As temáticas relacionadas à educação popular florescem da interação com movimentos sociais, grupos artísticos-literários, comunidades e escolas da zona rural e alunos de graduação e pós-graduação e suas famílias. Estas interações acontecem através da pesquisa, da extensão e

\footnotetext{
${ }^{6}$ Algumas destas pesquisas estão a seguir apresentadas: A construção do conhecimento entre alunos na ótica da coletividade: experiências partilhadas. (NASCIMENTO, J. S. K, 2020). Saberes de professoras no cotidiano: um estudo sobre processos de mediação em uma Unidade de Educação Infantil de Mossoró, Rio Grande do Norte. (NOGUEIRA, 2020); A Formação Inicial do Curso de Pedagogia da FE/UERN para Atuar na EJA (SOARES, Maria Cleoneide, 2018); Aspectos do protagonismo e da autonomia de professores na formação permanente docente (NASCIMENTO, M. A, 2021; Formação permanente: a partilha de experiências entre professoras da educação infantil do Município de Mossoró-RN (ANDRADE, 2021) A construção coletiva do projeto político-pedagógico: contribuições da educação popular à constituição da escola do/no campo (SILVA, F. E. B, 2018) O chão que me prende à liberdade: uma análise sobre educação do campo na Escola Valdemiro Pedro em Apodi/RN (COSTA, 2018); Afetos no processo de ensino-aprendizagem e nas interações de professoras e estudantes (SILVA, I. B, 2021).
} 
Ensino, Saúde e Ambiente - v. 14 n. esp. (2021): Dossiê Paulo Freire para além dos 100 anos: construir utopias, transformar a realidade, p. 659-684.

\section{Estética, Cinema, Teatro, Comunicação}

do ensino ${ }^{7}$ e envolvem saberes, fazeres e o acesso e permanência destes grupos e pessoas na educação formal.

A pesquisa e as ações realizadas no projeto de extensão Teatro Imagem na sala de Aula ${ }^{8}$ ampliam-se como metodologia potencializadora dos círculos de cultura lefreireanos. Embasadas numa pesquisa de caráter bibliográfico e exploratório, as técnicas e encenações do teatro imagem e do teatro fórum, seguidas pelas interações possíveis do fórum teatral, ocorrem como alongamento de leituras e estudos sistematizados em livros e artigos, promovendo o trabalho coletivo.

Os círculos voltados para o estudo teórico objetivam compreender cuidadosa e coletivamente a obra de Freire; (re) conhecer conceitos e elaborar tramas conceituais freireanas; conhecer alguns de seus interlocutores; e campos fundantes de ações práticas como a educação popular e os movimentos sociais.

Os círculos são momentos de encontro para problematização das temáticas. A realização de um círculo, para planejamento, permite que os proponentes discutam as situações percebidas nas realidades estudadas para fazer a "redução" que permite a definição do tema geral e das unidades temáticas, ou seja, dos subtemas, e a escolha dos dispositivos que provocarão as reflexões e produzirão conhecimento.

Os dispositivos são imagens, dramas, músicas, poesias e outras formas de expressão artística, entre elas as promovidas pelo teatro do oprimido, que representam os aspectos das realidades selecionados para estudo. Tais elementos, mobilizadores da cultura, encantam, provocam aquecimento afetivo, despertam lembranças, ideias, questionamentos, polêmicas e convicções que reverberam nos diálogos problematizadores. A disponibilização dos dispositivos é o ponto de partida para a identificação dos participantes com as temáticas em questão. Desta identificação surgem as falas significativas problematizadas no próprio círculo

\footnotetext{
${ }^{7}$ As disciplinas Educação Popular: perspectivas freireanas, do Curso de Pedagogia, e Movimentos Sociais e Educação Popular, do Mestrado em Educação pelo Programa de Pós-Graduação em Educação - POSEDUC, ambos da Faculdade de Educação - FE/UERN são espaços constantes de realização de círculos lefreireanos. Algumas das pesquisas de mestrado e graduação são: Saberes e fazeres do campo (LIRA, 2018); Centro de Estudos Bíblicos (CEBI) em Severiano Melo: uma experiência de educação popular (NASCIMENTO, Z. C. P, 2018); Estudar para ser gente?: os saberes escolares/acadêmicos na interface com os saberes da vida (SILVA, C. C, 2018); Escolarização e vida: narrativas e memórias dos servidores de apoio da FE/UERN, campus central (SOARES, 2015). O artigo Ditos, brincos e jogos populares no Lefreire (SILVA; XAVIER; BARBOSA, 2019) apresenta um círculo resultante de atividade de extensão.

8O Projeto de Extensão: Teatro Imagem na Sala de Aula consiste em estudos teóricos e exercícios corporais baseados no teatro do oprimido e realização de oficinas em escolas dos anos iniciais do ensino fundamental e da Educação de Jovens e Adultos. O produto dos estudos teórico-práticos é aplicado em círculos de culturas promovidos pelo LEFREIRE.
} 
Ensino, Saúde e Ambiente - v. 14 n. esp. (2021): Dossiê Paulo Freire para além dos 100 anos: construir utopias, transformar a realidade, p. 659-684.

\section{Estética, Cinema, Teatro, Comunicação}

ou em outros que o sucedam. A quantidade de círculos necessários para o estudo de cada tema é definida através da avaliação das contribuições ofertadas pela atividade aos participantes.

$\mathrm{Na}$ realidade de distanciamento físico provocada pela pandemia, os dispositivos, circunstancialmente imagens, são disponibilizadas aos convidados com antecedência, através da internet, em grupos no WhatsApp, para que esta interação prévia amplie e provoque questões a serem problematizadas durante o círculo virtual.

\section{PROBLEMATIZANDO PROCESSOS E CRIAÇÕES DOS CÍRCULOS DE CULTURA LEFREIREANOS}

Considerando o valor da leitura de mundo coletiva e do compartilhamento de experiências que reforçam as práticas e estabelecem diálogos e novas proposições para ações educativas libertadoras, o LEFREIRE se pergunta quais sentidos e significados ${ }^{9}$ pode atribuir às ações que realiza, uma vez que a busca por uma prática instigadora da participação recai no que se propõe como metodologias dinamizadoras dos seus círculos de cultura.

Este questionamento se desdobra em outros de cunho teórico-prático: Como fazer a reflexão (e a autorreflexão) crítica sem cair num pragmatismo desenfreado ou num pantanoso campo teórico? Como imprimir criatividade autoral às ações, preservando a essência freireana dos círculos de cultura? Como os pensamentos de Boal e Freire se cruzam nos círculos lefreireanos? Quais os atributos das imagens nos círculos? O coordenador/facilitador dos círculos de cultura e o animador/coringa do teatro do oprimido vislumbram e compartilham as utopias? Como se dão as interações entre os participantes em situação de distanciamento social? Algumas destas questões estão dirimidas pelo percurso formativo do Grupo. Outras fazem parte do seu processo de metarreflexão.

Entre os riscos do pragmatismo desenfreado e da aridez teórica, para entender o que de fato sustenta as práticas dos círculos de cultura, muito se pode buscar nas experiências populares coletivas e, também, evidentemente, acadêmicas. De maneira geral, estas características teórico-práticas situam-se na bifurcação entre os conhecimentos populares e os científicos, por associação entre ambos e/ou por problematizações desta relação.

\footnotetext{
${ }^{9}$ A compreensão lefreireana deste par dialético de conceitos decorre de uma pesquisa realizada junto ao Grupo de Estudos e Pesquisas Educação e Subjetividades da Faculdade de Educação da UERN sobre as aproximações e distanciamentos teóricos entre Paulo Freire e Vigotski (MARQUES; BARBOSA; SOARES, 2019).
} 
Ensino, Saúde e Ambiente - v. 14 n. esp. (2021): Dossiê Paulo Freire para além dos 100 anos: construir utopias, transformar a realidade, p. 659-684.

\section{Estética, Cinema, Teatro, Comunicação}

A relação entre saberes populares e científicos é tema de estudo de alguns círculos lefreireanos. Neles, os participantes partilham experiências de vida e aprendizagens de fazeres como a agricultura, a medicina popular, a arte e o artesanato. A identificação subjetiva e coletiva com as vivências que emergem nas falas partilhadas articula e sistematiza sentidos e significados atribuídos a estes saberes e resulta na elaboração individual e coletiva, fundamentada em leituras da área, dos conceitos relativos aos saberes e à educação popular.

O conhecimento popular se desenvolve, de maneira espontânea, pela observação, pela imitação e pela transformação criativa. Sua produção comporta diversos aspectos, tais como: os elementos, tanto materiais quanto culturais, disponíveis em cada momento e lugar para esta (re)elaboração; os saberes já produzidos e as suas formas de disseminação ${ }^{10}$; as transformações resultantes de mudanças de compreensão comuns a cada tempo histórico, como é o caso da substituição de materiais e de tecnologias necessárias à sustentabilidade planetária; e a conservação ou as transformações decorrentes da intervenção educativa.

Nas interações promovidas nesses círculos lefreireanos é possível compreender que nenhuma experiência de saber-fazer é totalmente igual à outra em função do esforço manualcognitivo desprendido, pois cada sujeito que (e)labora acrescenta algum detalhe, algum modo de fazer pessoal e vai transformando aquele fazer e o seu produto. E é esta transformação criativa de cada um e de todos, a partir daquilo que já existe, que garante a continuidade dos saberes de modo que as transformações resultantes do saber-fazer nas diversas realidades históricas vão modificando estas mesmas realidades.

Este caráter social e simbólico de (re) criação coletiva que possuem os saberes populares, porém, é transpassado por dimensões ideológicas e políticas típicas de “[...] uma cultura alienada, produtora de sucessivas estruturas sociais de dominação e tradutora de sequentes esquemas simbólicos de valores, conhecimentos e princípios de relações sob controle de grupos e classes dominantes [...]" (BRANDÃO, 2002, p. 45). A compreensão e transformação deste caráter alienante e opressor do conhecimento popular é tarefa da educação libertadora.

$\mathrm{Na}$ prática acadêmica, por sua vez, o conhecimento, fruto das ações de pesquisa e extensão, reverbera no processo de ensino e aprendizagem. Porém, a contribuição da pesquisa para a realidade pesquisada não é linear e óbvia. "O que se produz enquanto conhecimento nas reflexões e pesquisas na academia socializa-se não de imediato, mas em uma temporalidade

10 Tradicionalmente transmitidos de geração a geração através da oralidade, esses saberes vão transformando sua forma de disseminação na medida das condições que a sociedade cria e disponibiliza, como é o caso das tecnologias virtuais de informação e comunicação que expandem a sua transmissão, atualmente. 
Ensino, Saúde e Ambiente - v. 14 n. esp. (2021): Dossiê Paulo Freire para além dos 100 anos: construir utopias, transformar a realidade, p. 659-684.

\title{
Estética, Cinema, Teatro, Comunicação
}

histórica. [...] Uma construção lenta de conhecimento que se acumula em muitos anos" (GATTI, 2007, p. 34-35). Exigências institucionais influenciam no tempo disponível para produção do conhecimento nas universidades de maneira que a pesquisa nem sempre consegue dar respostas imediatas aos problemas da realidade.

Outra inquietação é que o conhecimento produzido socialmente nem sempre se reverte em ações transformadoras na vida daqueles que a produziram. Na área da educação, por exemplo,

\begin{abstract}
Para algumas vertentes de pesquisa [...], a escola é um lócus de busca do material necessário para produzir conhecimentos sobre a prática educativa. Porém, este conhecimento, produzido ao largo do seu lócus original, muitas vezes é apenas parcial e posteriormente devolvido a quem o deve ter por direito (NASCIMENTO, H. M. F. do, 2011, p. 26).
\end{abstract}

Nem sempre alcançando a contribuição desejada, a produção acadêmica corre o risco de se perder nos labirintos das políticas de publicização dos órgãos financiadores da pesquisa. Através da realização de círculos lefreireanos, uma pesquisa de trabalho de conclusão de curso estudou como o conhecimento é produzido na relação entre a universidade e a escola argumentando que:

\begin{abstract}
As possibilidades e os desafios tanto da universidade quanto da escola pública são diversos e interferem tanto na realização da pesquisa quanto nas contribuições que podem promover à aproximação entre essas duas instâncias de produção do conhecimento. Quando a pesquisa é feita através da problematização da realidade, este contato oportuniza o diálogo e, para isto acontecer, é necessário que a universidade conheça a escola, o que demanda tempo e condições estruturais e pedagógicas (NASCIMENTO, M. A., 2018, p. 41).
\end{abstract}

Considerando os desafios e as possibilidades das diversas formas de produção e disseminação do conhecimento e da cultura, a proposição dialógica e dialética de explicação da realidade compreende-os em suas diversas matizes, não sendo necessário abdicar de uma para reconhecer outras.

A preocupação com os sentidos e significados das ações lefreireanas também se debruça sobre a autoria e originalidade dos seus círculos. Então, o que diz Freire quando se refere ao "método" ou, amplamente falando, à proposição de uma educação marcada pela criticidade e 
Ensino, Saúde e Ambiente - v. 14 n. esp. (2021): Dossiê Paulo Freire para além dos 100 anos: construir utopias, transformar a realidade, p. 659-684.

\title{
Estética, Cinema, Teatro, Comunicação
}

busca da transformação do mundo por meio da palavra e da ação, e não pela justaposição de informes ou prescrições "doadas":

\begin{abstract}
O método completo que deveriam utilizar os líderes revolucionários não pode ser o da propaganda libertadora. Tampouco podem concentrar-se os líderes em sugerir aos oprimidos uma crença na liberdade, pensando ganhar assim a confiança. O método correto é o diálogo. A convicção dos oprimidos de que devem lutar por sua libertação não é um presente dos líderes revolucionários, mas o resultado de sua própria conscientização (FREIRE, 2006a, p. 99).
\end{abstract}

Nesta perspectiva, há que se considerar o alerta freireano sobre a necessidade de diferenciar conscientização de propaganda libertadora, inclusive quando ele afirma que "ninguém educa ninguém, ninguém se educa a si mesmo, os homens se educam entre si, mediatizados pelo mundo". Esta diferença talvez esteja na raiz da distinção entre uma vanguarda revolucionária que se propõe a conduzir as massas e a tarefa (trans)formadora construída pelos educadores que considera a mediação e a elaboração crítica e coletiva.

A essência da consciência é ser com o mundo e esta situação é contínua e inevitável. Conseqüentemente (sic), a consciência é, por essência, um "caminho para" algo fora de si mesma, que a rodeia e que ela apreende graças a seu poder de "idealização". Portanto, a consciência é, por definição, um método no sentido mais geral da palavra (FREIRE, 2006a, p. 100).

Na compreensão proposta por Freire (2006a), o conceito de método não se enquadra nos limites de um rol de ações pré-determinadas, prescrições a serem reproduzidas por outrem. Trata-se, isto sim, de uma estratégia de pensamento crítica e criativa voltada à educação libertadora. Nesta compreensão, imagens, palavras ou temas captados na realidade dos educandos geram, se conectam e/ou incorporam análises sociais, culturais e políticas reverberadas da condição de vida das pessoas e comunidades, compondo uma potência desencadeadora de discussões e práticas reflexivas.

A mesma preocupação com o equilíbrio entre criatividade autoral e preservação da essência do pensamento freireano leva a reflexões sobre o formato do círculo de cultura que, originalmente, não se adequa a molduras tradicionais de ensino reprodutoras de lógicas universais de conteúdo que não dão conta de sujeitos e subjetivações locais. Isto porque ele surge, numa primeira instância, do que é, ou se quer, popular. Paulo Freire assim o apresenta: 
Ensino, Saúde e Ambiente - v. 14 n. esp. (2021): Dossiê Paulo Freire para além dos 100 anos: construir utopias, transformar a realidade, p. 659-684.

\author{
Estética, Cinema, Teatro, Comunicação
}

\begin{abstract}
Em lugar de professor, com tradições fortemente "doadoras", o Coordenador de Debates. Em lugar de aula discursiva, o diálogo. Em lugar de aluno, com tradições passivas, o participante de grupo. Em lugar dos "pontos" e de programas alienados, programação compacta, "reduzida" e "codificada" em unidades de aprendizado (FREIRE, 2006b, p. 111).
\end{abstract}

Pelas suas características problematizadoras do status quo, o modo de atuação do círculo de cultura rompe com o formalismo instituído nas práticas educativas conservadoras. A força das motivações emancipadoras desta ruptura explica a ampliação e a amplitude deste modus operandi.

A princípio, a ideia de círculo de cultura como efetivo deslocamento do espaço regular do ensino institucionalizado para ambientes educativos diversos é uma ação que subverte a noção de escola em sua concepção "doadora", conforme Freire (2006b, p 111). Fundamentalmente, o círculo de cultura perspectiva a ruptura dos ritos e relações tradicionais de ensino e seus conteúdos programáticos orientados por uma base curricular unificada.

A força que põe o círculo em movência nasce da liberdade possível daquelas pessoas que comungam suas vivências e visões de mundo e de um coordenador que não exerce papel de professor, mas, na condição de animador, instiga o acontecimento através do diálogo.

A ênfase na participação, no espaço onde as vozes do grupo e as escutas atuam, exige uma facilitação problematizadora e promotora de narrativas cujo conteúdo se amplia no entendimento da realidade. Por esses vieses, torna-se possível elencar um tema gerador que venha instigar ações transformadoras das condições indesejadas pelo grupo.

Esta compreensão ampla de círculo de cultura não significa o puro antagonismo com relação à educação formal, escolar ou não escolar. O cerne da concepção de educação popular, construída a partir da iniciativa e das necessidades do povo, traz uma ampla contribuição ao conceito de escola em sua dimensão democrática e progressista, aquela que contempla um projeto político pedagógico verdadeiramente originário da realidade local e suas necessidades ${ }^{11}$. Isto porque, embora a criação da escola pública e universal corresponda à ideia de educação para, prescinde da compreensão de educação feita pelo povo.

O embate de forças entre a concepção popular de escola, partindo da realidade da comunidade em que se insere, e a necessidade de diretrizes institucionais, geralmente impostas

\footnotetext{
11 Algumas experiências freireanas institucionais, como as da sua gestão na Secretaria de Educação de São Paulo, apontaram para fazer da escola pública uma escola popular cidadã.
} 
Ensino, Saúde e Ambiente - v. 14 n. esp. (2021): Dossiê Paulo Freire para além dos 100 anos: construir utopias, transformar a realidade, p. 659-684.

\section{Estética, Cinema, Teatro, Comunicação}

verticalmente, amplia a reflexão sobre o necessário equilíbrio entre a preservação da essência do pensamento freireano e a criatividade autoral exigida para sua continuidade.

Considerando as problematizações acima levantadas, a preocupação metarreflexiva sobre sentidos e significados das ações de pesquisa e extensão do LEFREIRE, alimentada pelas leituras dos textos freireanos, sintetiza-se na compreensão da diferença entre a extensão bancária e a comunicação libertadora (FREIRE, 2002) impulsionada pelo diálogo que se dá nos círculos de cultura.

\section{TEATRO IMAGEM NA SALA DE AULA: AÇÕES LEFREIREANAS NO FORMATO REMOTO}

A práxica lefreireana tem acentuado um repertório de dinâmicas coletivas cujas escolhas reafirmam as abordagens de cunho participativo e democrático que se desdobram em acontecimentos expressivos resultantes das condições contextuais do Grupo. Assim é com as ações do Teatro imagem na sala de aula. Nelas, situações opressoras percebidas na comunidade e/ou vivenciadas pelos participantes merecem atenção e originam os diálogos críticos.

Tais questões problematizadoras, convertidas em temas geradores, se revertem em cenas experimentadas inicialmente nos ensaios como ações dramáticas, práxis dos processos educativos, potencialmente ampliando reflexões sobre o lugar, suas características, sua construção e relações políticas interpessoais que nele se dão.

Nos laboratórios dramáticos são exercitados jogos do teatro imagem, do teatro jornal e do teatro fórum cujas dinâmicas compõem as modalidades do teatro do oprimido sistematizado pelo pedagogo teatral Augusto Boal, modo peculiar de uma poética política concebida em ações diferenciadas das convenções teatrais clássicas. O produto dessas experimentações é compartilhado com o público através dos círculos lefreireanos numa práxica boaliana na qual o espectador já não mais se compraz com a prática clássica do teatro que separa e distribui o espaço do espetáculo, ou seja, o palco e a plateia.

Após as cenas serem apresentadas, o animador/coringa inicia o fórum com provocações sobre o tema e os papéis representados, convidando as pessoas a substituírem os personagens que supostamente consideram como opressores ou oprimidos de maneira a questionar suas posturas e problematizar as relações de opressão. Cada participante do jogo interpreta o papel na cena escolhida, improvisando as falas, tendo sua identidade confundida com a do personagem (BOAL, 1980). 
Ensino, Saúde e Ambiente - v. 14 n. esp. (2021): Dossiê Paulo Freire para além dos 100 anos: construir utopias, transformar a realidade, p. 659-684.

\section{Estética, Cinema, Teatro, Comunicação}

As cenas e o fórum provocam não apenas o diálogo de forma verbal, mas de maneira atitudinal pela ação do espectador que ensaia a sua reação ao se colocar no lugar do personagem. As várias intervenções, mediadas pelo animador/coringa, problematizam as situações e as posturas das pessoas diante das cenas, levando-os a refletir sobre uma situação em que inicialmente são ouvintes passivos, saindo da resignação, passando pela indignação e chegando, talvez, à compreensão de sua própria postura frente às situações opressoras, ou seja, se posicionando no limiar da ação-reflexão-ação.

As atividades e estudos desenvolvidos pelo Teatro imagem na sala de aula se pautam no ato presencial. Porém, considerando que a condição de distanciamento social impossibilita o fazer teatral, já que este necessita a presença física, nesta situação atípica e de forma emergencial, o Grupo teve que reorientar suas ações, optando pelo trabalho com imagens no formato remoto. Esta opção aguçou o questionamento sobre os atributos das imagens nos círculos lefreireanos.

Ficou evidente, logo à primeira vista, que as leituras, os diálogos e as técnicas com imagens, paradas ou em movimento, seriam possíveis à distância através do espaço virtual do Google sala de aula. Neste formato, jogos improvisacionais permitiram a criação de imagens fotográficas. As fotos produzidas inicialmente buscavam representar uma opressão vivenciada por cada participante no momento pandêmico.

Ao serem partilhadas as imagens, visualizou-se como as "narrativas" denunciavam opressões da sobrecarga do trabalho em home office de docentes, estudantes, mães, pais e donas/os de casa que acumulavam tarefas. As imagens individuais, observadas no coletivo, entoavam uma história vivenciada por muitas pessoas em seus cotidianos.

Este exercício dialógico sobre as situações-limites emergentes permitiu a síntese do tema que expressava os interesses do momento: $\mathrm{O}$ distanciamento social aumentou as horas do trabalho doméstico, sobretudo das mulheres, reafirmando explorações e acentuando conflitos de gênero nas famílias e, muitas vezes, a violência.

Com a delimitação do tema, foi-se compondo uma dramaturgia, um roteiro. Percebeuse, então, que a criação estava tomando forma de uma fotonovela. Sendo este um subgênero literário voltado para o público feminino, porém de alcance massificado nos anos 50 e 60, alienante com seus temas sentimentais, psicologicamente rasos, e personagens estereotipados, é uma imitação de todas as artes, um pastiche. Entretanto, esta cultura de massa deixa, na sua entranha, espaço para que, ao subverter as intenções e formatos controladores e inculcadores 
Ensino, Saúde e Ambiente - v. 14 n. esp. (2021): Dossiê Paulo Freire para além dos 100 anos: construir utopias, transformar a realidade, p. 659-684.

\section{Estética, Cinema, Teatro, Comunicação}

de valores sociais e morais (HABERT, 1974) por ela propostos, seja possível transformá-la em uma linguagem crítica e interativa viabilizadora da problematização de temáticas polêmicas.

Assim, num exercício de subversão de linguagens estereotipadas, surgiu a modalidade cênica denominada "fotonovela $\mathrm{dx}$ oprimidx", texto dramático composto de imagens fotográficas distribuídas em tirinhas contendo balões com falas e expressões dos personagens. $\mathrm{Na}$ verdade, a primeira fase de uma metodologia e modalidade do trabalho com imagens e textos que emergiram dos experimentos remotos do Grupo.

Neste processo coletivo de criação dramatúrgica, a cada encontro o texto ia tomando forma. A leitura e a discussão das fotos permitiram a construção paulatina dos personagens, primeiro nomeando-os e, posteriormente, detalhando suas histórias de vida, profissão e posturas, o que foi essencial para definir suas falas e atitudes que os caracterizavam como oprimidos ou opressores.

Em seguida começou-se a montagem da história em dois formatos: As fotos foram montadas em tirinhas e acrescentados balões com as falas. E, de outra forma, as tirinhas se tornaram roteiro para a criação de imagens em movimento, filmadas individualmente por cada participante e editadas para compor um vídeo contendo as cenas e diálogos mantidos pelos personagens. As imagens em movimento, didaticamente, apresentavam as mesmas cenas das imagens paradas expressas em forma de tirinhas da fotonovela.

A redução temática e a criação dramática resultaram na "Fotonovela dx oprimidx: “Trabalha ou é só dona de casa?”, vivência fictícia de uma família típica da realidade pandêmica, com seus desafios e dificuldades. A história apresenta como o trabalho consome uma dona de casa que tem, sob sua responsabilidade, as tarefas domésticas e o cuidado com todos os membros da família, sem tempo para si e para qualquer realização profissional. O texto dramático traz a discussão sobre o trabalho não remunerado das donas de casas e as opressões dessa atividade. As imagens e falas, "no limite da ficção e da própria realidade" (BOAL, 1980), revelam e/ou denunciam o cotidiano de conflitos e violação dos direitos humanos em que a sociedade e os indivíduos estão imersos.

Após os diversos ensaios restritos ao grupo, a "Fotonovela" foi apresentada em dois círculos: um ensaio aberto e a estreia oficial. As encenações constaram da leitura dramática das tirinhas, apresentadas em power point, dando vida às opressões expressas; e da exibição do vídeo. A justaposição de tirinhas e vídeo objetivou proporcionar uma melhor assimilação do texto dramático apresentado no formato remoto, inclusive de pessoas com deficiências. Da mesma forma, as cenas foram apresentadas mais de uma vez para que os/as espectadores/as 
Ensino, Saúde e Ambiente - v. 14 n. esp. (2021): Dossiê Paulo Freire para além dos 100 anos: construir utopias, transformar a realidade, p. 659-684.

\section{Estética, Cinema, Teatro, Comunicação}

pudessem identificar aquelas que seriam objeto de sua intervenção no fórum, momento em que o animador/coringa problematizou o conteúdo da encenação e convidou-os a expor como reagiriam se estivessem na situação apresentada e a recriar as cenas. Assim, a cada cena recriada, outras pessoas repensavam as situações e interviam.

$\mathrm{O}$ ensaio aberto objetivou perceber como os participantes iriam interagir com o formato criado pelo Grupo para que fossem feitos ajustes e adequações. A estreia ocorreu pouco tempo depois do ensaio, confirmando a percepção que os lefreireanos têm, continuamente, de que ninguém sai dos encontros sem inquietações que ficam reverberando em suas reflexões acerca dos diálogos ali iniciados.

No ínterim entre os dois círculos, o Grupo pode avaliar os papéis exercidos, as provocações do animador/coringa e a inserção dos participantes na dramatização. Foi possível perceber como a encenação levou as pessoas a pensarem sobre si, suas posturas e ações diante das cenas, causando um estranhamento inicial, mas também uma reflexão sobre seu posicionamento em relação às opressões. Quando se propunham a mudar as cenas, "espectatores" e "espect-atrizes" falavam sobre como já haviam vivenciado aquela imagem em suas vidas. Portanto, se viam nas personagens e queriam alterar a própria postura, ou reafirmar a conduta já adotada.

Foi problematizado durante a avaliação como as pessoas veem quem são os opressores, os oprimidos e os que se oprimem, oscilando suas posturas frente às situações, pois, na tentativa de enfrentar as opressões, por vezes, os espect-atores e espect-atrizes assumiam a roupagem do opressor. Esta perspectiva do oprimido "carregar" em si o opressor foi antes aqui discutida a partir das considerações de Paulo Freire. Para o autor, é necessário que os oprimidos superem a opressão a partir do reconhecimento crítico da situação.

Daí a necessidade que se impõe de superar a situação opressora. Isto implica no reconhecimento crítico, na "razão" desta situação, para que, através de uma ação transformadora que incida sobre ela, se instaure uma outra, que possibilite aquela busca do ser mais (FREIRE, 1981, p. 35).

A avaliação permitiu perceber que a ação transformadora buscada através do fórum realizado no círculo do ensaio aberto, ao provocar o questionamento sobre o risco de se definir um sujeito ou grupo apenas como opressor ou apenas como oprimido, reverberou nas reflexões do fórum do círculo da estreia. Eis que novas perspectivas foram apresentadas pelos que dialogavam com as cenas. As falas de enfrentamento ao opressor traziam outra conotação, não 
Ensino, Saúde e Ambiente - v. 14 n. esp. (2021): Dossiê Paulo Freire para além dos 100 anos: construir utopias, transformar a realidade, p. 659-684.

\section{Estética, Cinema, Teatro, Comunicação}

eram mais tão imersas em resignação ou revolta, mas na tentativa de dialogar. Neste sentido, a substituição de personagens identificados como opressores ocorreu não mais apenas para confrontá-los, pois uma personagem compreendida como opressora foi substituída na tentativa da espect-atriz compreender e argumentar que sua postura (da personagem) se fazia por conta das próprias opressões internalizadas, expressas direta ou indiretamente em seu discurso.

O processo de ação-reflexão-ação acontece de forma diferente para cada pessoa e, nos círculos lefreireanos, mediados pelos diálogos e escutas, os participantes podem se posicionar e refletir a partir das falas dos outros e suas diferentes perspectivas que, por vezes, confrontam as ideias iniciais de cada um ou trazem concepções não percebidas anteriormente. A interação promovida pelo animador/coringa no fórum se configura como uma oportunidade de açãoreflexão-ação em que os participantes vão, coletivamente, tecendo uma compreensão crítica das situações que possibilitam o "ser mais".

\section{O ANIMADOR E AS FACILITAÇÕES DOS CÍRCULOS DE CULTURA}

O coordenador/facilitador dos círculos de cultura e o animador/coringa do teatro do oprimido vislumbram e compartilham as mesmas utopias? Uma vez que para Freire a utopia não é passiva, ela para "ser mais", se quer atuante na ação-reflexão-ação, na práxis dialógica, democrática, participativa, na qual as pessoas pensam e apreendem a realidade. Práxis esta potencializada, no teatro do oprimido, pela atuação de um animador/coringa que propõe um teatro libertador das amarras da passividade, possibilitando a transformação do espectador e da espectadora críticos da sua condição de público receptáculo para a de espect-ador/espect-atriz atuantes que não se satisfazem em apenas criticar a cena, mas se propõem a atuar, transformando-a.

É sabido da função do coordenador do círculo de cultura como uma das funções expressivas para o acontecimento desta práxica. A potência da facilitação possibilita um estado de comunhão coletiva que, humanamente, resvala no diálogo, fazendo incidir sobre a realidade questões impulsionadoras de ações e reflexões do grupo sobre a sua própria condição de estar no mundo.

Vê-se que as funções do coordenador e do animador necessitam estar potencializadas numa abordagem poética política que se pretende, sobremaneira, expressa no movimento de 
Ensino, Saúde e Ambiente - v. 14 n. esp. (2021): Dossiê Paulo Freire para além dos 100 anos: construir utopias, transformar a realidade, p. 659-684.

\section{Estética, Cinema, Teatro, Comunicação}

agir e pensar. De certo modo, os jogos e exercícios do teatro do oprimido vêm, coordenados pelo "coringa", somar-se às metodologias de facilitação dos círculos.

O coordenador/facilitador não impõe temas ou ações, motiva o grupo a encontrar seus temas. Por isto mesmo, o papel de animador/coringa parece proporcionar o estado espontâneo necessário ao compartilhamento das situações vivenciadas, ao exercício da liberdade para a liberdade. Seja nos jogos do teatro do oprimido ou na introdução com imagens como disparador de diálogos nos círculos lefreireanos, o modus operandi demonstra o processo criativo do grupo e o coloca, ou não, como prática para a liberdade.

O animador/coringa, que é sujeito de extrema relevância no grupo, merece certo debruçar acerca de suas diversificações e variantes ao longo dos tempos e, sobretudo, por se entender que esta função é merecedora de uma pesquisa que norteie o pensamento de uma prática de educação para liberdade que se faz numa constância como força que emana do manifesto da cultura de cada grupo.

Educador, professor, animador, facilitador, coordenador do círculo de cultura, assume um papel que poderá ou não situar a prática como libertadora, senão, vejamos: Uma pessoa que, escolhida pelo grupo, passa a animar o círculo. Não se trata de um especialista, com uma formação específica da animação, ou seja, não precisa ter uma formação específica, ser um professor ou estar estudando pedagogia. Pelo contrário, no círculo, ensinar e aprender se dão no mesmo movimento. É a comunidade/grupo se reconhecendo e construindo a sua linguagem, a sua estética educativa, pedagógica, de formação. Construção que se faz a partir de cada lugar, do que se faz com o que se aprende.

Neste sentido, embora alguns círculos aconteçam direcionados para ter coordenações específicas, os facilitadores/animadores surgem do próprio grupo, as pessoas que coordenam ou que socializam experiências nem sempre são pessoas ditas "escolarizadas". Às vezes, não sabem ler, decodificar palavras escritas, mas "dão aula", sabem outras habilidades e conhecimentos históricos e culturais da comunidade. Isto é o que coloca o círculo como ação para a liberdade, como atuação democrática participativa.

Este modo de acontecer se contrapõe aos modos imperativos de interação. Faz-se contraposição a uma concepção especializada, do expert, entranhado na história das universidades, da verticalização das relações entre os diversos tipos de conhecimento, do saber, do não saber, do acúmulo de conteúdos nem sempre significantes. Tem-se uma distorção do acúmulo de conhecimento, por exemplo, no momento em que a fala especializada apresenta uma erudição, mas é incompreendida pelas classes populares. Ao contrário, o saber está em 
Ensino, Saúde e Ambiente - v. 14 n. esp. (2021): Dossiê Paulo Freire para além dos 100 anos: construir utopias, transformar a realidade, p. 659-684.

\section{Estética, Cinema, Teatro, Comunicação}

favor da transformação quando o facilitador/animador convive, tem experiência e conhecimento da realidade dos locais onde os círculos se realizam.

O facilitador/coordenador/animador/coringa não traz o tema definido, mobiliza o grupo e o aquece com jogos integrativos e ações problematizadoras com o intuito de que o grupo dê os rumos temáticos e todas as pessoas expressem suas palavras na busca pela conscientização e transformação. Tal práxis só se faz possível via atitudes não bancárias efetivadas nos círculos de cultura.

\section{CONSIDERAÇÕES}

Este tempo histórico selado por tantos antagonismos está a exigir a transição dialética entre a denúncia e o anúncio, conforme compreensão de Paulo Freire. Nele, se faz mister que o estudo cuidadoso e coletivo permita a compreensão cada vez maior da amplitude da contribuição freireana à educação. Convém a cada educador e a cada grupo comprometido com este pensamento identificar os limites e as possibilidades de sua compreensão sobre ele e, mais ainda, ter clara a contribuição que oferta àqueles com quem compartilha ações e reflexões.

Em seu processo metarreflexivo, o LEFREIRE busca constantemente identificar a contribuição de seus círculos de cultura para a construção de conhecimentos e possíveis transformações dela decorrentes. O desejo incessante dos pesquisadores-extensionistas de responderem aos "por quês?" e aos "como?" que envolvem a problematização das realidades desperta sempre novas perguntas e este exercício de ação-reflexão-ação é imprescindível ao movimento de resistência que a sociedade anseia.

Neste momento histórico de necessária busca pelo amor, o Grupo se pergunta até onde o afeto pronunciado que envolve os círculos lefreireanos reverbera em modificações nas vidas das pessoas com quem interage? Considerando-se que "Não é possível a pronúncia do mundo, que é um ato de criação e recriação, se não há amor que a infunda” (FREIRE, 2005, p. 91-92.), este argumento faz emergir questionamentos sobre as bases de uma educação libertadora fundada no amor e suas movências.

Paulo Freire ensina que o amor "Como o ato de valentia, não pode ser piegas; como ato de liberdade, não pode ser pretexto para a manipulação, senão gerador de outros atos de liberdade" (FREIRE, 2005, p. 92). O amor libertador, que se compromete com o diálogo com os oprimidos e, em decorrência, também com os opressores, não pode ter uma postura acrítica, subjetivista e romantizada, mas sim ser um ato de valentia que principia por distinguir visões de mundo diferentes de visões de mundo equivocadas e perversas. 
Ensino, Saúde e Ambiente - v. 14 n. esp. (2021): Dossiê Paulo Freire para além dos 100 anos: construir utopias, transformar a realidade, p. 659-684.

\section{Estética, Cinema, Teatro, Comunicação}

A reflexão e a autorreflexão críticas que o Grupo anseia o impulsiona a evitar o pragmatismo através do estudo cuidadoso dos conceitos freireanos e de sua interpretação na realização de práticas educativas populares, escolares e acadêmicas criativas inspiradas e fundamentadas no referencial freireano, e boaliano, de maneira a contribuir para a conservação e inovação dos dispositivos da educação libertadora. Neste sentido se direcionam os dispositivos que impulsionam e viabilizam os círculos de cultura lefreireanos.

O tempo de hoje urge à sociedade brasileira, novamente, uma alfabetização crítica que ainda não se efetivou. Para além dos índices alarmantes que apontam os que ainda não sabem ler e escrever, os indicadores sociais mostram que há um longo caminho de desafios a serem enfrentados pelos que acreditam na força mobilizadora e transformadora dos círculos de cultura.

\section{REFERÊNCIAS}

ANDRADE, A V de. Formação permanente: a partilha de experiências entre professoras da educação infantil do Município de Mossoró-RN. Dissertação (Mestrado em Educação). Mossoró, RN, Universidade do Estado do Rio Grande do Norte, 2021.

BRANDÃO, C R. A educação como cultura. Campinas-SP: Mercado das Letras, 2002.

BOAL, A. Stop: C'est Magique. Rio de Janeiro. Ed. Civilização Brasileira. 1980.

COSTA, F C de M. O chão que me prende à liberdade: uma análise sobre educação do campo na Escola Valdemiro Pedro em Apodi/RN. Dissertação (Mestrado em Educação). Mossoró/RN. Universidade do Estado do Rio Grande do Norte, 2018.

FIORI, E M. Aprender a dizer a sua palavra. Prefácio. In: FREIRE, Paulo. Pedagogia do Oprimido. $43^{\mathrm{a}}$ edição. Rio de Janeiro. Paz e Terra, 2005.

FREIRE, P. Extensão ou Comunicação. 12ª edição. Rio de Janeiro: Paz e Terra, 2002.

FREIRE, P. Pedagogia do Oprimido. 9a edição. Rio de Janeiro. Paz e Terra, 1981.

FREIRE, P. Conscientização: Teoria e prática da libertação: Uma introdução ao pensamento de Paulo Freire. $3^{\mathrm{a}}$ edição. São Paulo: Centauro, 2006a.

FREIRE, P. Educação como prática da liberdade. $29^{\mathrm{a}}$ edição. Rio de Janeiro: Paz e Terra, $2006 b$.

FREIRE, P. Pedagogia do Oprimido. 43a edição. Rio de Janeiro: Paz e Terra, 2005.

GATTI, B A. A construção da pesquisa em educação no Brasil. Brasília: Líber Livro Editoras, 2007. 
Ensino, Saúde e Ambiente - v. 14 n. esp. (2021): Dossiê Paulo Freire para além dos 100 anos: construir utopias, transformar a realidade, p. 659-684.

Estética, Cinema, Teatro, Comunicação

GERMANO, J W. De pé no chão também se aprende a ler: Política e educação no Rio Grande do Norte - 1960 - 1964. Dissertação. Universidade Estadual de Campinas. Instituto de Filosofia e Ciências Humanas. Mestrado de Sociologia. Campinas, 1981.

GERMANO, J W. As quarenta horas de Angicos. Educação \& Sociedade, V 18, ano XVIII, no 59, p. 389-393, 1997. Disponível em: https://www.scielo.br/scielo.php?script=sc i arttext\&pid=S0101-73301997000200009. Acesso em 10 de março de 2021.

HABERT, A B. Fotonovela e Indústria Cultural: estudo de uma forma de literatura sentimental fabricada para milhões. Petrópolis: Vozes, 1974.

LIRA, K C de G. Saberes e fazeres do campo. Dissertação (Mestrado em Educação). Mossoró/RN. Universidade do Estado do Rio Grande do Norte. Coordenação de Aperfeiçoamento de Pessoal de Nível Superior, 2018.

MARQUES, A B; BARBOSA, S M C; SOARES, M C de. CO-LABOR-AÇÃO: elaboração coletiva de estratégias de pesquisa. In: NASCIMENTO H M F do; ROCHA DE LIMA, H J; SOARES, M C. (Orgs.). ENSINO, PESQUISA, EXTENSÃO: PERSPECTIVAS FREIREANAS. 1ed.Mossoró: EDUERN, 2019, v. 1, p. 1-246.

NASCIMENTO, H M Fa do. Círculo de Ação-Reflexão-Ação: uma possibilidade praxiológica para a prática pedagógica da formação de professores: Universidade Federal do Rio Grande do Norte. Programa de Pós-Graduação em Educação. Natal, 2011.

NASCIMENTO, M A do. Pesquisa e produção do conhecimento na relação entre a universidade e a escola. Trabalho de Conclusão de Curso (Graduação). Mossoró/RN, Universidade do Estado do Rio Grande do Norte, 2018.

NASCIMENTO, M A do. Aspectos do protagonismo e da autonomia de professores na formação permanente docente. Dissertação (Mestrado em Educação). Mossoró, RN, Universidade do Estado do Rio Grande do Norte, 2021.

NASCIMENTO, Z C P do. Centro De Estudos Bíblicos (CEBI) em Severiano Melo: uma experiência de educação popular. Dissertação (Mestrado em Educação). Mossoró/RN, Universidade do Estado do Rio Grande do Norte, 2018.

NASCIMENTO, J S K do. A construção do conhecimento entre alunos na ótica da coletividade: experiências partilhadas. Dissertação (Mestrado em Educação) Mossoró/RN, Universidade do Estado do Rio Grande do Norte, 2020.

NOGUEIRA, M da C A. Saberes de professoras no cotidiano: um estudo sobre processos de mediação em uma Unidade de Educação Infantil de Mossoró, Rio Grande do Norte. Dissertação (Mestrado em Educação). Mossoró/RN, Universidade do Estado do Rio Grande do Norte, 2020.

SILVA, S C do C. Estudar para ser gente?: os saberes escolares/acadêmicos na interface com os saberes da vida. Dissertação (Mestrado em Educação). Mossoró/RN, Universidade do Estado do Rio Grande do Norte, 2018. 
Ensino, Saúde e Ambiente - v. 14 n. esp. (2021): Dossiê Paulo Freire para além dos 100 anos: construir utopias, transformar a realidade, p. 659-684.

Estética, Cinema, Teatro, Comunicação

SILVA, F E B da. A construção coletiva do projeto político-pedagógico: contribuições da educação popular à constituição da escola do/no campo. Dissertação (Mestrado em Educação). Mossoró/RN, Universidade do Estado do Rio Grande do Norte, 2018.

SILVA, I B da. Afetos no processo de ensino-aprendizagem e nas interações de professoras e estudantes. Faculdade de Educação/UERN (Monografia), Mossoró/RN, 2021.

SILVA, E L de A; XAVIER, J K do N D e; BARBOSA, E H da S C. Ditos, brincos e jogos populares no Lefreire. In: NASCIMENTO, H M Fa do; LIMA, H J R de; SOARES, M C. (Org.) Pesquisa, Ensino, Extensão: Perspectivas Freireanas. 01ed., Mossoró, RN: EDUERN, 2019. p. $155-169$

SOARES, M C. A Formação Inicial do Curso de Pedagogia da FE/UERN para Atuar na EJA. Dissertação (Mestrado em Educação). Mossoró/RN, Universidade do Estado do Rio Grande do Norte, 2018.

SOARES, L D. Escolarização e vida: narrativas e memórias dos servidores de apoio da FE/UERN, campus central. Trabalho de Conclusão de Curso (Graduação em Pedagogia). Mossoró/RN. Universidade do Estado do Rio Grande do Norte, 2015.

WEFFORT, F C. Educação e Política: Reflexões sociológicas sobre uma pedagogia da Liberdade. Prefácio. In FREIRE, P. Educação como prática da liberdade. $29^{a}$ edição. Rio de Janeiro: Paz e Terra, 2006.

\section{SOBRE AS AUTORAS E O AUTOR}

\section{HÉLIO JUNIOR ROCHA DE LIMA}

Doutor em Estudos da Linguagem (UFRN), mestre em Artes Cênicas (UFRN) especializado em Pedagogia do Teatro e coordenação de jogos com fundamentação pedagógica pela Theaterpädagogische Akademie BuT - Bundesverband Theaterpädagogik e. V. , Heidelberg/Alemanha e graduado em Pedagogia (UERN). Tem experiência na educação formal e não-formal, no litoral e no campo, atuando com crianças, adolescentes, adultos e idosos. Discute aspectos de processos criativos de leitura e escrita através do texto dramático, de jogos e exercícios teatrais atravessados por teorias instigadoras de ações emancipadas (Augusto Boal) e de redistribuição da ordem do sensível (Rancière) associadas ao plano de pensamento de Deleuze e Guatarri no que tange aos planos territoriais, as desterritorializações e reterritorializações como desdobramentos políticos da pedagogia e da arte. Atualmente é professor adjunto da Universidade do Estado do Rio Grande do Norte UERN e do Programa de Pós-Graduação em Educação POSEDUC, atuando na área de corporeidade e ensino de arte, com interesse na linha de pesquisa: práticas educativas, cultura, diversidade e inclusão. 
Ensino, Saúde e Ambiente - v. 14 n. esp. (2021): Dossiê Paulo Freire para além dos 100 anos: construir utopias, transformar a realidade, p. 659-684.

Estética, Cinema, Teatro, Comunicação

\section{HOSTINA MARIA FERREIRA DO NASCIMENTO}

Professora do Curso de Pedagogia e do Programa de Pós-Graduação em Educação da Universidade do Estado do Rio Grande do Norte, graduada em pedagogia (1989) e doutora em educação pela Universidade Federal do Rio Grande do Norte (2011). Experiência na área de educação, com ênfase em ensino-aprendizagem, abordando principalmente os seguintes temas: o pensamento de Paulo Freire, formação de professores, história de vida, educação popular e educação do campo. Tutora egressa do PET Pedagogia da UERN. Coordenadora da atividade de extensão Diálogos em Paulo Freire e Educação Popular - LEFREIRE.

\section{MARIA CLEONICE SOARES}

Professora Assistente II do Departamento de Educação da Universidade do Estado do Rio Grande do Norte - UERN. Mestre em Educação pelo Programa de Pós-Graduação em Educação da Universidade do Estado do Rio Grande do Norte - POSEDUC/UERN. Licenciada em Pedagogia pela Faculdade de Educação da UERN. Tem como principal linha de investigação a Formação Inicial de professores; Educação Popular; Estudos em Paulo Freire; Estudos relacionados a psicologia da educação; Estágio Supervisionado; Estudo da Realidade, teatro do oprimido. Coordena o Projeto de Extensão LEFREIRE - Diálogos em Paulo Freire e Educação Popular. Participa do Grupo de Pesquisa Educação e Linguagens - GEPEL, na linha Educação Popular, História e Memória. Membro do Projeto de Extensão Leitura e Escrita na Sala de Aula. Membro do Projeto de Extensão Teatro Imagem na sala de aula. Membro do Grupo de Pesquisa Formação e Profissionalização Docente. Membro da Cátedra Paulo Freire RN. 